\title{
Parâmetros utilizados na avaliação do metabolismo do ferro em cães
}

\author{
Iron metabolism parameters in dogs
}

\section{Luciana Salini Abrahão Pires ${ }^{\text {I }}$ Rosangela Locatelli Dittrich ${ }^{\text {II }}$ Andressa Cristina Souza ${ }^{\text {II }}$ Melina Andrea Formighieri Bertol ${ }^{\mathrm{III}}$ Lia Fordiani Lenati Patricio ${ }^{\mathrm{III}}$}

\section{RESUMO}

A avaliação do metabolismo de ferro associado aos resultados hematológicos constitui uma ferramenta importante para o diagnóstico, controle e diferenciação de estados anêmicos. $O$ presente trabalho objetivou determinar os parâmetros utilizados na avaliação do metabolismo do ferro (ferro sérico, capacidade latente de ligação do ferro, capacidade total de ligação do ferro, indice de saturação do ferro, transferrina e ferritina) em cães sadios. Foram selecionados 120 cães, divididos em quatro grupos de sexo e faixa etária distintos (30 machos jovens e 30 adultos, 30 fêmeas jovens e 30 adultas). As amostras de sangue foram coletadas das $8 \mathrm{~h}$ às $11 \mathrm{~h}$, com os cães em jejum. Os valores médios para as concentrações de ferro sérico, capacidade latente de ligação do ferro, capacidade total de ligação do ferro, índice de

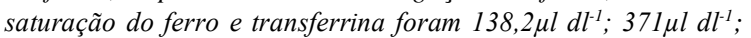
$232,6 \mu \mathrm{l} \mathrm{dl^{-1 }} ; 37,7 \%$ e $259,6 \mathrm{mg} \mathrm{dl}^{-1}$, respectivamente. Esses indices foram avaliados quanto às variações entre sexo e idade. Os valores médios foram submetidos ao teste de Tukey e não apresentaram variação significativa $(P<0,01)$. A concentração de ferro sérico apresentou-se mais elevada em cães machos adultos, comparados aos machos jovens $(P<0,05)$. $O$ valor de ferritina obtido foi inferior a 1 ng $\mathrm{mL}^{-1}$ com reagente comercial de imunoensaio quimioluminescente para humanos.

Palavras-chave: capacidade latente de ligação do ferro, capacidade total de ligação do ferro, índice de saturação do ferro, ferritina, transferrina.

\section{ABSTRACT}

The determination of iron metabolism rates associated with hematological findings is an important tool to diagnosis, control and differentiation of anemic states. This

\begin{abstract}
study has as objective to determine the iron parameters (serum iron, unsaturated iron binding-capacity, total iron bindingcapacity, transferrin saturation rate (IST), transferrin and ferritin) in healthy dogs. It was selected 120 dogs, shared in four different groups of sex and age (30 young males and 30 adult males, 30 young females and 30 adult females). The blood samples were collected between 8 and $11 \mathrm{~h}$ AM, with fasted dogs. The average values to serum iron, unsaturated iron binding-capacity, total iron-binding-capacity, transferring

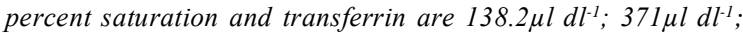
$232.6 \mu \mathrm{l} \mathrm{dl^{-1 }} ; 37.7 \%$ e $259.6 \mathrm{mg} \mathrm{dl}^{-1}$ respectively. These rates were evaluated according to sex and age variation. The average values submitted to Tukey test it were not significant $(P<0,01)$. Considering a 5\% level variation of error probability, the serum iron was higher in adult male dogs, comparing with young male ones $(P<0,05)$. The ferritin values were 0ng $\mathrm{ml}^{-1}$ in human chemiluminescent immunoassay kit.
\end{abstract}

Key words: unsaturated iron binding-capacity, total iron binding-capacity, ferritin, transferrin.

\section{INTRODUÇÃO}

O ferro é um elemento fundamental à manutenção da vida, com participação obrigatória e indispensável no processo hematológico, além de fazer parte das moléculas de mioglobina, citocromos e enzimas, como a peroxidase e catalase (ANDREWS \& SMITH, 2000).

O conhecimento da dinâmica do metabolismo do ferro, ou seja, absorção, circulação e

'Faculdade Evangélica do Paraná (FEPAR), 80730-000, Curitiba, PR, Brasil. E-mail: lusapires@hotmail.com. Autor para correspondência.

IDepartamento de Medicina Veterinária, Universidade Federal do Paraná (UFPR), Curitiba, PR, Brasil.

IIIUFPR, Curitiba, PR, Brasil. 
armazenamento é fundamental no estudo das causas e efeitos das anemias. Os parâmetros utilizados para a avaliação do metabolismo do ferro, transferrina (proteína transportadora do ferro), ferritina e hemossiderina (formas de reserva do ferro), complementam o exame hematológico e auxiliam na compreensão da causa da anemia e, consequentemente, no seu tratamento. Dessa forma, constituem-se importantes ferramentas para o clínico veterinário monitorar pacientes anêmicos.

A constatação da deficiência de ferro nem sempre é tão evidente, pois o cão pode apresentar os níveis de ferro sanguíneo normais, mas apresentar a ferritina diminuída. Esta, por sua vez, pode oscilar conforme os níveis de reserva de ferro no organismo, mas também em casos de um processo inflamatório agudo, em que se apresenta em níveis elevados (ANDREWS \& SMITH, 2000).

A determinação dos parâmetros ligados ao metabolismo do ferro complementa as análises hematológicas e bioquímicas na avaliação clínica da anemia, sendo imprescindível nos casos de deficiência desse mineral (LISTE et al., 1994). A concentração plasmática do ferro sérico indica a quantidade do íon que está sendo transportado ligado à transferrina, o qual se apresenta diminuído nas anemias ferroprivas (LEWIS et al., 2005). A determinação plasmática tem sido estabelecida por métodos colorimétricos que separam o íon da transferrina, reduzindo-o ao estado ferroso e ligando-o a um cromóforo para a sua quantificação medida pela intensidade de cor desenvolvida (SYNERMED, 2003).

A transferrina é a proteína de transporte do ferro e é expressa pela capacidade de ligação com o íon, indicada pela capacidade latente de ligação (CLLF) somada ao ferro sérico, resultando na capacidade total de ligação do ferro (CTLF). Pode ser determinada por métodos colorimétricos (SMITH, 1989). Apresenta-se elevada nas anemias ferroprivas e com valores reduzidos nas anemias por doença crônica (JAIN, 2000; WALLACH \& KANAAN, 2003; LEWIS et al., 2005).

A ferritina sérica reflete os estoques corpóreos totais de ferro, é a principal proteína de reserva deste metal no organismo. As técnicas para a determinação da ferritina sérica são reações dirigidas por anticorpos, como radioimunoensaio, ELISA, imunoturbidimetria e quimioluminescência, de alta sensibilidade. Os reagentes comerciais de ELISA para a dosagem de ferritina sérica em cães já foram desenvolvidos nos Estados Unidos (WEEKS et al., 1988; ANDREWS et al., 1992) e no Japão (WATANABE et al., 2000), no entanto, não são comercializados, devido ao custo elevado para a produção inviabilizando sua exportação.
Existe a carência de valores do metabolismo do ferro específicos para a população de cães no Brasil. Atualmente, são utilizados parâmetros estabelecidos nos Estados Unidos (FELDMAN et al., 1981; HARVEY et al., 1982; WEEKS et al., 1989) e que indicam valores gerais para a espécie, não havendo separação entre sexo e idade.

O objetivo do presente trabalho foi determinar os valores do ferro sérico, capacidade de ligação do ferro e ferritina sérica de 120 cães sadios, machos e fêmeas, adultos e jovens, da região de Curitiba.

\section{MATERIAL E MÉTODOS}

Seleção dos animais

Foram selecionados 120 cães procedentes de cinco canis de criadores particulares. Os canis dispunham de recintos individuais semi-cobertos com área média de $6 \mathrm{~m}^{2}$ e área para lazer. Para este estudo, os animais foram subdivididos em quatro grupos, segundo os critérios de idade e sexo: 30 fêmeas jovens; 30 fêmeas adultas; 30 machos jovens e 30 machos adultos. Para a categoria dos cães jovens, foram utilizados animais entre três e 12 meses de idade e para os cães adultos, animais de 13 meses a oito anos de idade. Foram utilizados cães das raças Beagle, Pastor Alemão, Rottweiler e Retriever do Labrador.

Todos os cães foram submetidos a um manejo sanitário adequado, vacinados anualmente e desverminados a cada quatro meses. As atividades físicas desempenhadas pelos animais foram semelhantes nos diferentes canis e os cães recebiam alimentação balanceada, segundo os níveis de exigência por categoria. Foram utilizados somente cães sadios, segundo a anamnese, exame clínico, hematológico, bioquímico e coproparasitológico.

$\mathrm{Na}$ anamnese e exame clínico completo, observou-se a ausência de processo inflamatório nos três meses anteriores, coloração normal de mucosa oral e conjuntival, ausência de lesão dermatológica e de sinais de lesão no sistema locomotor, linfonodos normais à palpação, ausculta pulmonar e cardíaca normais, ausência de ectoparasitas. Os critérios como ausência de cio, de gestação e lactação foram adotados para as fêmeas.

Coletas das amostras

Os cães estavam em jejum de 8 a 10 horas, foram imobilizados por contenção física e o sangue foi obtido por punção das veias cefálica ou jugular. Foi realizada uma coleta de sangue por animal, entre às $8 \mathrm{~h}$ e 11h. O sangue foi imediatamente acondicionado em dois tubos distintos, um com o anticoagulante 
etilenodiaminotetracetato de sódio (EDTA), para a realização do hemograma, e o outro sem o anticoagulante destinado às dosagens de uréia, creatinina e às provas ligadas ao metabolismo do ferro, sendo mantidos sob refrigeração até o momento das análises laboratoriais. Os esfregaços sanguíneos foram realizados imediatamente após a coleta e acondicionados para posterior coloração no laboratório.

Foram coletadas amostras individuais de fezes dos animais e mantidas em geladeira $\left(4 \mathrm{a} 8^{\circ} \mathrm{C}\right)$ até o momento do exame coproparasitológico.

\section{Análises laboratoriais}

As análises hematológicas, bioquímicas e dos parâmetros relacionados ao metabolismo do ferro foram realizadas no Laboratório de Patologia Clínica Veterinária e as coproparasitológicas, no Laboratório de Parasitologia, ambos do Hospital Veterinário da Universidade Federal do Paraná.

As contagens de eritrócitos, de leucócitos e a determinação da concentração de hemoglobina foram realizadas no equipamento CELM CC530. O volume globular (hematócrito) foi realizado pela técnica do microhematócrito. O volume globular médio (VGM) e a concentração de hemoglobina média (CHGM) foram obtidos pelas fórmulas de Wintrobe (JAIN, 2000). Nas extensões sanguíneas coradas (Wright) foram realizadas a contagem diferencial de leucócitos e as avaliações morfológicas dos eritrócitos e leucócitos. As concentrações de proteína plasmática total foram obtidas por refratometria. $\mathrm{O}$ fibrinogênio foi obtido pelo método de precipitação pelo calor (KANEKO \& SMITH, 1967). As dosagens de uréia, creatinina e a determinação da atividade sérica da enzima alaninatransaminase (ALT) foram realizadas pelo método enzimático GLDH, método cinético do picrato alcalino e método cinético, respectivamente, no analisador semiautomático CELM SBA 200. As amostras de fezes foram analisadas pela técnica de flutuação Willis-Molay para pesquisa de ovos de helmintos e oocistos de protozoários.

As amostras de soro para análise do ferro foram mantidas refrigeradas entre 2 e $8^{\circ} \mathrm{C}$ por, no máximo, uma semana até a análise. Os frascos utilizados na manipulação das amostras eram descartáveis e de plástico, para evitar a contaminação com traços de ferro.

O ferro sérico foi determinado pelo método colorimétrico de Goodwin modificado (FERROZINE), com reagente comercial da In Vitro, Diagnóstica S/A, Itabira, Minas Gerais. Foram utilizados $250 \mu 1$ de soro de cada amostra e as leituras feitas em espectrofotômetro (METROLAB ${ }^{\circledR} 330$ ), na faixa de $565 \mathrm{~nm}$.
A capacidade ligadora do ferro foi determinada pelo método colorimétrico de Goodwin modificado (FERROZINE), com reagente comercial In Vitro, Diagnóstica S/A, Itabira, Minas Gerais. Foram utilizados $250 \mu$ de soro de cada amostra e as leituras feitas em espectrofotômetro (METROLAB ${ }^{\circledR} 330$ ), na faixa de $560 \mathrm{~nm}$. A amostra foi incubada com uma solução padrão de ferro $\left(500 \mu \mathrm{g} \mathrm{dl}^{-1}\right)$ em meio tamponado $(\mathrm{pH}$ 8,3 ). Ocorreu a saturação dos sítios disponíveis para o ferro na transferrina. Feita a adição do reagente de cor (ferrozine), o excesso de ferro não ligado formou um complexo magenta, determinando a capacidade latente de ligação do ferro (CLLF). A capacidade ligadora do ferro foi determinada para a obtenção dos valores da capacidade latente de ligação do ferro (CLLF) e da capacidade total de ligação do ferro (CTLF).

A partir da obtenção da CTLF, obteve-se o valor da transferrina pela fórmula:

$\operatorname{TRF}\left(\mathrm{mg} \mathrm{dl}^{-1}\right)=\operatorname{CTLF} \times 0,7$

Obteve-se também o índice de saturação da transferrina pela fórmula:

IST $(\%)=($ Ferro sérico/CTLF $) \times 100$

Devido à inexistência de reagente comercial para dosagem de ferritina canina, realizou-se um teste piloto com reagentes para seres humanos. Os soros dos cães foram analisados pelos métodos de imunoensaio quimioluminescente de micropartículas (CMIA), ARCHITECT Ferritina ${ }^{\circledR}$, para análise quantitativa de ferritina de seres humanos, da ABBOTT Laboratórios do Brasil Ltda. As análises foram processadas em equipamento automático do Sistema ARCHITECT, no Laboratório de Imunologia do Hospital de Clínicas da UFPR. As amostras também foram processadas pelo método enzima imunoensaio quimioluminescente para aparelho automatizado IMMULITE-1000 Systems (Diagnostic Products Corporation, USA), para análise quantitativa de ferritina humana, em Laboratório particular, localizado em Sorocaba, São Paulo.

$\mathrm{O}$ delineamento utilizado foi inteiramente casualisado com arranjo fatorial $(2 \times 2)$, considerando o fator sexo (macho ou fêmea) e o fator idade (jovens ou adultos). Foram usadas 28 repetições por tratamento. Os dados foram submetidos à análise de variância com auxílio do programa computacional GENES (CRUZ, 2006). As médias foram comparadas com o teste de Tukey ao nível de 1 e 5\% de probabilidade. A amplitude da variação das médias foi estimada pelo intervalo de confiança e pelo desvio padrão.

\section{RESULTADOS}

Foram estabelecidos os valores médios dos parâmetros de ferro por categoria de sexo e idade. A 
concentração de ferro não apresentou diferenças significativas para o fator sexo $(\mathrm{P}<0,05)$, porém as médias do fator idade, jovens e adultos, diferem estatisticamente $(\mathrm{P}<0,05)$. Os valores do ferro sérico de adultos foram superiores aos dos jovens. Não houve interação entre os fatores sexo e idade para a concentração de ferro (Tabela 1).

As análises estatísticas da capacidade total de ligação do ferro (CTLF), transferrina e porcentagem de saturação da transferrina (IST\%) não apresentaram diferenças significativas para os fatores sexo e idade, não havendo interação entre os fatores $(\mathrm{P}<0,05)$. Os valores da CLLF não apresentaram diferenças significativas para os fatores sexo e idade, no entanto, apresentaram interação entre estes $(\mathrm{P}<0,05)$. Os valores entre os animais adultos (machos e fêmeas) não apresentaram variação significativa. No entanto, entre os jovens, houve variação entre o sexo, sendo o valor dos machos superior ao das fêmeas $(\mathrm{P}<0,05)$. Entre as fêmeas, não houve variação significativa entre jovens e adultas. Entretanto, entre os machos, a variação foi significativa $(\mathrm{P}<0,05)$, sendo que a média dos jovens foi superior à dos adultos (Tabela 1).

Nas análises da ferritina, pelo método de imunoensaio quimioluminescente de micropartículas
(CMIA) e pelo método enzima imunoensaio quimioluminescente, todas as amostras resultaram na mesma leitura: $<1,0 \mathrm{ng} \mathrm{mL}^{-1}$ (inferior a 1,0).

\section{DISCUSSÃO}

As concentrações de ferro encontradas no presente trabalho foram obtidas pelo método colorimétrico e foram aproximadamente 1,6 vezes maiores do que as obtidas com o método columétrico, utilizado para cães (WEEKS et al., 1989). Essa variação possivelmente é devido à diferença dos métodos. Segundo SMITH (1989), o método columétrico não apresenta interferência de outros compostos do soro, como lipídios e colesterol, o que poderia explicar essa variação encontrada. HARVEY et al. (1982) obtiveram valores próximos $\left(149 \mu \mathrm{g} \mathrm{dL}^{-1}\right)$ também pelo método colorimétrico. LISTE et al. (1994) verificaram valor médio de ferro sérico superior $\left(181,7 \mathrm{ng} \mathrm{dL}^{-1}\right)$, com a utilização de um método colorimétrico (batofenantrolina), entretanto utilizaram amostras de oito cães.

Não houve diferença significativa relativa ao sexo, entre os cães deste estudo, como também observado por outros autores (LISTE et al., 1994; COELHO et al., 2006; MUNDIN, 2008). Além disso, o

Tabela 1 - Valores médios dos parâmetros do ferro de cães, por categoria de sexo e idade.

\begin{tabular}{|c|c|c|c|c|c|}
\hline & ------------. & ------------------ & & -----------. & ---------------- \\
\hline Ferro $\left(\mu \mathrm{g} \mathrm{dL}^{-1}\right)$ & Média & $\mathrm{IC}^{*}$ & & Média & IC \\
\hline Jovens & $112,6 \mathrm{bA}^{1}$ & $93,7-131,5$ & & $149,4 \mathrm{bA}$ & $123,6-175,1$ \\
\hline Adultos & $136,6 \mathrm{aA}$ & $120,2-152,9$ & & $154,3 \mathrm{aA}$ & $134-174,6$ \\
\hline CV (\%) & & & 38,4 & & \\
\hline \multicolumn{6}{|l|}{$\operatorname{CTLF}\left(\mu \mathrm{g} \mathrm{dL}{ }^{-1}\right)$} \\
\hline Jovens & $381,8 \mathrm{aA}$ & $352,1-411,5$ & & $365,7 \mathrm{aA}$ & $343,4-387,9$ \\
\hline Adultos & $356,1 \mathrm{aA}$ & $326,4-385,8$ & & $380,6 \mathrm{aA}$ & $345,3-415,8$ \\
\hline $\mathrm{CV}(\%)$ & & & 20,9 & & \\
\hline \multicolumn{6}{|l|}{ IST $\%$} \\
\hline Jovens & $29,3 \mathrm{aA}$ & $24,8-33,8$ & & $40,8 \mathrm{aA}$ & $34,2-47,3$ \\
\hline Adultos & $39,3 \mathrm{aA}$ & $34,8-43,8$ & & $41,4 \mathrm{aA}$ & $36,6-46,1$ \\
\hline $\mathrm{CV}(\%)$ & & & 31,2 & & \\
\hline \multicolumn{6}{|c|}{ Transferrina $\left(\mathrm{mg} \mathrm{dL}^{-1}\right)$} \\
\hline Jovens & $266,9 \mathrm{aA}$ & $246,1-287,7$ & & $256 \mathrm{aA}$ & $240,4-271,6$ \\
\hline Adultos & $249,3 \mathrm{aA}$ & $228,5-270,1$ & & $266,4 \mathrm{aA}$ & $241,7-291,1$ \\
\hline $\mathrm{CV}(\%)$ & & & 20,9 & & \\
\hline \multicolumn{6}{|l|}{ CLLF $\left(\mu \mathrm{g} \mathrm{dL}^{-1}\right)$} \\
\hline Jovens & $268,3 \mathrm{aA}$ & $243,5-293$ & & $216,3 \mathrm{aB}$ & $187,4-245,2$ \\
\hline Adultos & $219,5 \mathrm{bA}$ & $194,7-244,2$ & & $226,3 \mathrm{aA}$ & $195,3-257,3$ \\
\hline $\mathrm{CV}(\%)$ & & & 31,2 & & \\
\hline
\end{tabular}

Médias seguidas pela mesma letra minúscula nas colunas não diferem entre si pelo teste de Tukey em nível de 5\% de probabilidade; *IC Intervalo de Confiança (95\%);

CV - Coeficiente de variação; CLLF - capacidade latente de ligação do ferro; CTLF - Capacidade total de ligação do ferro; IST - Índice de saturação da transferrina.

Ciência Rural, v.41, n.2, fev, 2011. 
resultado foi diferente do encontrado em seres humanos, em que se evidenciou diferença entre os sexos, com valores elevados tanto para os homens jovens como adultos (YIP et al., 1984).

Neste estudo, os valores de ferro foram significativamente inferiores para os cães jovens ( $\mathrm{P}<0,05)$, o mesmo observado por MUNDIN (2008). Fato que pode ser explicado pela elevada demanda exigida pelo organismo na fase de crescimento (SMITH, 1997).

Existem divergências quanto aos horários das coletas de sangue para determinação das concentrações de ferro, porque os níveis de ferro sérico oscilam devido a uma variação circadiana, que resulta da variação na liberação do ferro do sistema reticuloendotelial para o plasma, conforme os níveis de cortisol sérico (COOK et al., 1992; WORWOOD, 2001). No entanto, DALE et al. (2002) não observaram um padrão consistente de variação entre os diferentes horários do dia ( $8 \mathrm{~h}$ da manhã, meio dia e 4h da tarde), indicando que não há necessidade de se restringir a coleta de material a um horário específico do dia.

HARVEY et al. (1982), também pelo método colorimétrico, relataram valores da CLLF e do índice de saturação do ferro, $243 \mu \mathrm{g} \mathrm{dL} \mathrm{dL}^{-1}$ e $39,3 \%$, respectivamente, para 35 cães sadios, divididos igualmente entre machos e fêmeas, sem a especificação da faixa etária dos animais.

Os testes de recuperação por meio das análises de ferritina com os reagentes comerciais humanos foram realizados, porém os resultados foram inferiores a $1 \mathrm{ng} \mathrm{mL}^{-1}$, revelando a incapacidade de leitura das amostras caninas e a especificidade de antígenos para o teste destinado aos seres humanos. Em estudo utilizando-se reagente comercial específico para ferritina canina, foram encontrados valores normais de $62 \mathrm{ng} \mathrm{mL}^{-1}$ (WEEKS et al., 1989) e de 298ng $\mathrm{mL}^{-1}$ (WATANABE et al., 2000). Apesar da alta homologia entre os aminoácidos das cadeias de ferritina humana e canina, $\mathrm{H}=96 \%$ e L=86\% (ORINO et al., 2005), supõese que a porção de ferritina humana purificada, utilizada nos reagentes comerciais para seres humanos, possui uma sequência de aminoácidos não homóloga à ferritina canina. Sendo assim, os valores da ferritina canina não foram considerados neste estudo.

Até o presente momento, não existem, descritos na literatura, outros valores para os parâmetros do ferro em cães sadios no Brasil.

O ferro sérico e a capacidade ligadora do ferro podem ser analisados como rotina nos laboratórios de patologia clínica veterinária.

\section{CONCLUSÃO}

Podem ser adotados para cães os valores de ferro sérico, CLLF, CTLF, IST e transferrina encontrados neste estudo. A determinação da ferritina canina pelos métodos de quimioluminescência humana não fornece uma leitura confiável.

\section{AGRADECIMENTOS}

Os autores agradecem às instituições públicas e privadas, que permitiram o uso dos seus cães para a coleta de amostras para este experimento. Agradecem aos acadêmicos e residentes do Hospital Veterinário, que participaram durante as etapas da pesquisa.

\section{COMITÊ DE ÉTICA E BIOSSEGURANÇA}

O presente trabalho foi aprovado pelo Comitê de Ética no Uso de Animais do Setor de Ciências Agrárias (CEUASCA) da Universidade Federal do Paraná.

\section{REFERÊNCIAS}

ANDREWS, G.A. et al. An improved ferritin assay for canine sera. Veterinary Clinical Pathology, v.21, p.57-60, 1992.

ANDREWS, G.A.; SMITH, J.E. Iron metabolism. In: FELDMAN BF et al. Schalm's veterinary hematology. 5.ed. Baltimore: Lippincott Williams \& Wilkins, 2000. p.129134.

COELHO, A.O.et al. Influência dos fatores etários e sexuais nos valores de ferro sérico e seus metabólitos em cães da raça doberman. Veterinaria Notícias, v.12, n.2, p.101, 2006.

COOK, J.D. Clinical evaluation of iron deficiency. Seminars in Hematology, v.19, p.6-18, 1982.

COOK, J.M. et al. Iron deficiency and the measurement of iron status. Nutrition Research Revew, v.5, p.189-202, 1992 .

CRUZ, C.D. Programa GENES: estatística experimental e matrizes. Viçosa: UFV, 2006. 285p.

DALE, J.C. et al. Diurnal variation of serum iron, iron-binding capacity, transferrin saturation, and ferritin levels. American Journal of Clinical Pathology, v.117, p.802-808, 2002. Disponível em: <http://ajcp.ascpjournals.org/content/117/5/ 802.long>. Acesso em: 15 fev. 2009.

FELDMAN, B.F.et al. Anemia of inflammatory disease in the dog: ferrokinetics of adjuvant-induced anemia. American Journal of Veterinary Research, v.42, n.4, p.583-585, 1981.

HARVEY, J.W. et al. Chronic iron deficiency anemia in dogs. Journal of the American Animal Hospital Association, v.18, p.946-960, 1982.

JAIN N.C. Blood loss or hemorrhagic anemias. In: FELDMAN, B.F. et al. Schalm's veterinary hematology. 5.ed. Baltimore: Lippincott Williams \& Wilkins, 2000. p.580-585. 
KANEKO, J.J.; SMITH, R. The estimation of plasma fibrinogen and its clinical significance in the dog. California Veterinarian, v.21, n.4, p.21-24, 1967.

LEWIS, S.M. et al. Hematologia prática de Dacie e Lewis. 9.ed. Porto Alegre: Artmed, 2005. 572p.

LISTE, F. et al. Metabolismo del hierro en perro: Aplicaciones diagnósticas de la determinación del estatus férrico y valores de referencia en la raza Beagle. Annals of Veterinary, v 9, n.10, p.75-81, 1994.

MONTEIRO, S.C.M. et al. Metabolismo do ferro. Ciência e Cultura, v.1, n.1, p. 11-18, 2006.

MUNDIM, A.V. Perfil bioquímico sérico em potros Bretão Postier e cães Doberman em fase de crescimento e de cabras Saanen nosdiferentes estádios delLactação. 2008. 76f. Tese (Doutorado em Genética e Bioquímica) - Universidade Federal de Uberândia, Uberlândia, MG.

ORINO, K. et al. Sequence analysis of canine and equine ferritin $\mathrm{H}$ and L subunit cDNAs. DNA Sequency, v.16, p.58-64, 2005.

SMITH, J.E. Iron metabolism and its disorders. In: KANEKO, $\mathrm{J} . \mathrm{J}$ et al. Clinical biochemistry of domestic animals. 5.ed. San Diego: Academic, 1997. p.223-239.
SYNERMED. Ferro sérico 600. Westfield, Indiana: Synermed International, 2003. p.33

WALLACH, J.; KANAAN, S. Interpretação de exames laboratoriais. Rio de Janeiro: Medsi, 2003. p.1088.

WATANABE, K. et al. Characterization of ferritin and ferritinbinding proteins in canine serum. BioMetals, v.13, p.57-63, 2000 .

WEEKS, B.R. et al. Enzyme linked immunosorbent assay for canine serum ferritin using monoclonal anti-canine ferritin. American Journal of Veterinary Research, v.49, p.11931195, 1988.

WEEKS, B.R. et al. Relationship of serum ferritin and iron concentrations and serum total iron-binding capacity to nonheme iron stores in dogs. American Journal of Veterinary Research, v.50, n.2, p.198-200, 1989.

WORWOOD, M. Iron-deficiency anaemia and iron overload. In: LEWIS, S.M. et al. (Eds). Practical haematology. 9.ed. London: Churchill Livingstone, 2001. p.115-128.

YIP, R. et al. Age-related changes in laboratory values used in the diagnosis of anemia and iron deficiency 1'2. American Journal of Clinical Nutrition, v.39, p.427-436, 1984. 